Marquette University

e-Publications@Marquette

4-8-1997

\title{
Mechanistic Studies on the Aminopeptidase from Aeromonas proteolytica: A Two-Metal Ion Mechanism for Peptide Hydrolysis
}

Guanjing Chen

Utah State University

Tanya Edwards

Utah State University

Ventris M. D'Souza

Utah State University

Richard C. Holz

Marquette University, richard.holz@marquette.edu

Follow this and additional works at: https://epublications.marquette.edu/chem_fac

Part of the Chemistry Commons

\section{Recommended Citation}

Chen, Guanjing; Edwards, Tanya; D'Souza, Ventris M.; and Holz, Richard C., "Mechanistic Studies on the Aminopeptidase from Aeromonas proteolytica: A Two-Metal Ion Mechanism for Peptide Hydrolysis" (1997). Chemistry Faculty Research and Publications. 302.

https://epublications.marquette.edu/chem_fac/302 
Marquette University

e-Publications@Marquette

\section{Chemistry Faculty Research and Publications/College of Arts and Sciences}

This paper is NOT THE PUBLISHED VERSION; but the author's final, peer-reviewed manuscript. The published version may be accessed by following the link in the citation below.

Biochemistry, Vol. 36, No. 14 (April 8, 1997): 4278-4286. DOI. This article is (C) American Chemical Society Publications and permission has been granted for this version to appear in $\underline{\mathrm{e}}-$ Publications@Marquette. American Chemical Society Publications does not grant permission for this article to be further copied/distributed or hosted elsewhere without the express permission from American Chemical Society Publications.

\section{Mechanistic Studies on the Aminopeptidase from Aeromonas proteolytica: A Two-Metal Ion Mechanism for Peptide Hydrolysis}

Guanjing Chen

Department of Chemistry and Biochemistry, Utah State University, Logan, Utah Tanya Edwards

Department of Chemistry and Biochemistry, Utah State University, Logan, Utah Ventris M. D'souz

Department of Chemistry and Biochemistry, Utah State University, Logan, Utah Richard C. Holz

Department of Chemistry and Biochemistry, Utah State University, Logan, Utah

SUBJECTS:

Inhibition, Anions, Peptides and proteins, Metals, Ions 


\section{Abstract}

The aminopeptidase from Aeromonas proteolytica (AAP) is uncompetitively inhibited by fluoride ion at $\mathrm{pH} 8.0$ with an inhibition constant $\left(K_{\mathrm{i}}\right)$ of $30 \mathrm{mM}$. Thus, fluoride inactivates AAP only after substrate binding, and only a single fluoride ion binds to AAP. On the other hand, chloride ion does not inhibit AAP up to concentrations of 2 $\mathrm{M}$ at $\mathrm{pH}$ 8.0. The $\mathrm{pH}$ dependence of fluoride inhibition of AAP was measured over the $\mathrm{pH}$ range 6.0-9.5.

Between $\mathrm{pH}$ values of 6.0 and 9.0, fluoride ion acts as a pure uncompetitive inhibitor of AAP, and the $K_{\mathrm{i}}$ increases from 1.2 to $370 \mathrm{mM}$. From a plot of $\mathrm{p} K_{\mathrm{i}} \mathrm{vs} \mathrm{pH}$, a p $K_{\mathrm{a}}$ value of $7.0 \pm 0.3$ was extracted which corresponds to a single deprotonation process. At $\mathrm{pH}$ values higher than 9.0, the fluoride inhibition pattern changes to competitive. This change in inhibition pattern was attributed to a change in ionic strength or perhaps $\mathrm{pH}$ of the solution since fluoride ion was also found to become a competitive inhibitor of AAP at pH 8.0 in the presence of $2 \mathrm{M} \mathrm{NaCl}$. These data, taken together with previous kinetic studies of mono- and dinuclear hydrolases with fluoride ion, suggest that a Zn(II)-bound water/hydroxide exists at the dimetal active site of AAP with a $\mathrm{p} K_{\mathrm{a}}$ of 7.0 and that this water/hydroxide acts as the active site nucleophile. The hydrolysis of I-leucine- $p$-nitroanilide was measured spectrophotometrically in triplicate between 25 and $85^{\circ} \mathrm{C}$ at eight substrate concentrations ranging from 5 to $800 \mu \mathrm{M}$. From these data, $K_{\mathrm{m}}$ values were derived at each temperature studied and were found to increase exponentially with increasing temperature. Moreover, the calculated $V_{\max }$ values were also found to increase over this temperature range, mimicking the $K_{\mathrm{m}}$ values. An Arrhenius plot was constructed from $k_{\text {cat }}$ values and was found to be linear over the temperature range $25-85^{\circ} \mathrm{C}$, indicating that the ratelimiting step in AAP peptide hydrolysis is product formation and does not change as a function of temperature. From the slope of the line, the activation energy $\left(E_{a}\right)$ was calculated to be $36.5 \mathrm{~kJ} / \mathrm{mol}$. The enthalpy and entropy of activation at $25^{\circ} \mathrm{C}$ calculated over the temperature range $298-358 \mathrm{~K}$ were found to be $34.0 \mathrm{~kJ} / \mathrm{mol}$ and -94.2 $\mathrm{J} /(\mathrm{mol} \cdot \mathrm{K})$, respectively. The free energy of activation at $25^{\circ} \mathrm{C}$ was found to be $62.1 \mathrm{~kJ} / \mathrm{mol}$. Combination of the available X-ray crystallographic data with the present kinetic and thermodynamic results, as well as the previously reported kinetic and spectroscopic data, has allowed a detailed catalytic mechanism for AAP to be proposed.

Aminopeptidases catalyze the hydrolysis of a wide range of $\mathrm{N}$-terminal amino acid residues from proteins and polypeptides. These enzymes have a broad substrate specificity and are widely distributed in bacteria, yeast, plant, and animal tissues (Taylor, 1993a,b). Functions of aminopeptidases include protein maturation, protein degradation, hormone level regulation, and cell-cycle control. In the cytosol of eukaryotes, all proteins are initiated with an $\mathrm{N}$-terminal methionine; however, almost all proteins undergo some form of maturation that includes $\mathrm{N}$-terminal processing. Aminopeptidases participate in the cleavage of methionine residues from the $\mathrm{N}$ termini of polypeptides which are essential to the posttranslational modification of the N-terminus of proteins, such as N-acetylation or N-myristoylation (Ben-Bassat \& Bauer, 1987; Ben-Bassat et al., 1987). The composition of mature $\mathrm{N}$-termini plays important roles in the directed degradation and cellular targeting of proteins. In addition, recent studies on the biochemical pathways involved in metastasis have revealed a set of proteinases and genes that play fundamental roles in tumor growth and proliferation (Liotta et al., 1991; Liotta, 1992). Since aminopeptidase activity has been reported on the surface of tumor cells (Aoyagi et al., 1976), they are very likely key players in tumor growth and metastastic proliferation.

Three aminopeptidases have been crystallographically characterized. Bovine lens leucine aminopeptidase (bILAP) ${ }^{1}$ contains a ( $\mu$-hydroxo)bis( $\mu$-carboxylato)dizinc(II) core with terminal carboxylates at each metal site along with a peptide backbone carbonyl and a lysine amine nitrogen bound to one of the $\mathrm{Zn}$ (II) ions (Burley et al., 1990, 1992; Sträter \& Lipscomb, 1995a,b). The Zn(II) ion bound by three aspartic acid residues and the lysine residue has been shown to be the tightly bound metal ion from $\mathrm{X}$-ray crystallographic results on the bILAP $\mathrm{Zn}(\mathrm{II})-\mathrm{Mg}(\mathrm{II})$ metal-substituted enzyme (Kim \& Lipscomb, 1993a,b) Methionine aminopeptidase from Escherichia 
coli (MAP) contains a bis( $\mu$-carboxylato)dicobalt(II) core with terminal carboxylates at each metal site along with a histidine residue at the second Co(II) site (Roderick \& Matthews, 1993). Each Co(II) ion resides in a distorted octahedral environment with the remaining coordination sites likely filled by water molecules. Interestingly, both MAP and bILAP have metal-metal distances of $2.9 \AA$. The third aminopeptidase from Aeromonas proteolytica (AAP) possesses a ( $\mu$-aqua) $(\mu$-carboxylato)dizinc(II) core with one terminal carboxylate and one histidine residue at each metal site (Chevrier et al., 1994). Both $\mathrm{Zn}(\mathrm{II})$ ions in AAP appear to reside in a distorted tetrahedral coordination geometry with a Zn-Zn distance of $3.5 \AA$. The structural motifs observed for these three aminopeptidases are unusual in comparison to mononuclear zinc proteases such as thermolysin, carboxypeptidases, and endopeptidases which contain histidine-rich coordination environments (Vallee \& Auld, 1990; Wilcox, 1996).

Many aspects of the hydrolytic chemistry catalyzed by the dinuclear metal clusters of aminopeptidases have gone unexplored. Recent X-ray crystallographic studies on transition state analog inhibited states of both bILAP and AAP have provided the most definitive evidence for structural possibilities of each catalytic step (Burley et al., 1990, 1992; Sträter \& Lipscomb, 1995a,b; Chevrier et al., 1996). Based on these data, a mechanism was proposed for bILAP in which both active site metal ions function as Lewis acids. In this mechanism, a bridging hydroxide ion acts as the nucleophile by attacking the scissile carbonyl carbon of the peptide substrate (Sträter \& Lipscomb, 1995a,b). For AAP, a mechanism like that of thermolysin or carboxypeptidase A was proposed since an active site carboxylate appears to hydrogen bond to the bridging oxygen atom of the transition state analog inhibitor d-iodophenylalanine hydroxamate (Chevrier et al., 1996). While these two aminopeptidases contain dinuclear Zn(II) active sites and have similar substrate specificities, they may in fact function by markedly different catalytic mechanisms.

In order to gain insight into the role of each metal ion in dinuclear hydrolases and to determine if one or both metal ions function as Lewis acids, we have explored the inhibition of AAP by fluoride ion. The use of simple anions to probe water or hydroxide binding to Zn(II) hydrolases is well established (Dixon et al., 1980; Bertini \& Luchinat, 1984; Vallee \& Galdes, 1984; Williams \& Auld, 1986; Ganzhorn \& Chanal, 1990; Vincent et al., 1991; Lee \& Nowak, 1992; Yang et al., 1994). Analyses of the kinetic data for the interaction of AAP with fluoride ion at $\mathrm{pH} \mathrm{8.0,} \mathrm{the} \mathrm{pH}$ of maximal activity for AAP, in conjunction with the $\mathrm{pH}$ dependence of the inhibition of AAP by fluoride ion, have allowed a detailed catalytic mechanism to be proposed for AAP. In addition, the temperature dependence of AAP catalysis has also been explored and is discussed in the context of the proposed mechanism and the activated enzyme-substrate complex. These data provide new insights into the roles of both metal ions in catalysis as well as the position of the hydroxylating agent in AAP.

\section{Materials and Methods}

\section{Purification of AAP.}

All chemicals used in this study were purchased commercially and of the highest quality available. The aminopeptidase from Aeromonasproteolytica was purified from a stock culture kindly provided by Professor Céline Schalk. Cultures were grown according to the previously published procedure (Prescott \& Wilkes, 1976) with minor modifications to the growth media. Briefly, the casein hydrolyzate medium was prepared by adding $200 \mathrm{~g}$ of Sigma Casein Enzymatic Hydrolyzate (N-Z-Amine AS from Bovine Milk) and $264 \mathrm{~g}$ of Instant Ocean (Aquarium Systems, Mentor, $\mathrm{OH}$ ) dissolved in $10 \mathrm{~L}$ of distilled water. The $\mathrm{pH}$ was adjusted to approximately 8.0-8.5, and the culture medium was placed in a New Brunswick $10 \mathrm{~L}$ fermentor and autoclaved for $45 \mathrm{~min}$. Upon cooling, a sterile solution of $1 \mathrm{~g}$ of $\mathrm{K}_{2} \mathrm{HPO}_{4}$ in $10 \mathrm{~mL}$ of $\mathrm{H}_{2} \mathrm{O}$ was added along with enough $\mathrm{ZnCl}_{2}$ to make the $10 \mathrm{~L}$ solution $0.1 \mathrm{mM}$ with respect to $\mathrm{Zn}(\mathrm{II})$. In addition, $2 \mathrm{~mL}$ of Sigma antifoam A was added to prevent frothing. The bulk culture was harvested $12 \mathrm{~h}$ following inoculation and filtered through a Pellicon Tangential Flow Filter $\left(0.22 \mu \mathrm{m}\right.$ cassettes, Millipore). Solid $\left(\mathrm{NH}_{4}\right)_{2} \mathrm{SO}_{4}(564 \mathrm{~g} / \mathrm{L})$ was added directly to the culture filtrate at $4{ }^{\circ} \mathrm{C}$ and 
stirred until all the ammonium sulfate dissolved. The resulting precipitate was collected $24 \mathrm{~h}$ later by filtering it through a $0.22 \mu \mathrm{m}$ filtration assembly (Corning tissue culture flasks). The solid was dissolved in a minimal volume of Tricine buffer, $\mathrm{pH} 8.0$, and dialyzed at $4^{\circ} \mathrm{C}$ for $18-24 \mathrm{~h}$ against two changes of the same buffer. The sample was then heated at $70^{\circ} \mathrm{C}$ for $5-7 \mathrm{~h}$, centrifuged, and dialyzed against $10 \mathrm{mM}$ Tricine, $\mathrm{pH} 8.0$, containing 1 $\mathrm{M} \mathrm{NaCl}$. The enzyme solution at this point was brown in color due to pigments that are tightly associated with AAP.

The enzyme was purified by the method of Schalk et al. (1992). Typically, $100 \mathrm{mg}$ of AAP was applied to an octylSepharose (Pharmacia) column $(3 \times 70 \mathrm{~cm})$ that had been previously equilibrated with $10 \mathrm{mM}$ Tricine buffer at $\mathrm{pH} 8.0$ and $1 \mathrm{M} \mathrm{NaCl}$. After extensive washing, the enzyme was eluted with $10 \mathrm{mM}$ Tricine buffer, $\mathrm{pH}$ 8.0, at a flow rate of $1 \mathrm{~mL} / \mathrm{min}$. AAP was shown to be pure by SDS-polyacrylamide gel; however, a small amount of the pigments associated with AAP still remained. To remove any additional $\mathrm{NaCl}$, the pooled fractions of AAP were dialyzed against three changes of $10 \mathrm{mM}$ Tricine buffer, $\mathrm{pH}$ 8.0. The remaining pigments were removed by applying AAP to a $1.5 \times 25 \mathrm{~cm}$ Q-Sepharose Fast Flow column (Pharmacia) that had been previously equilibrated with $10 \mathrm{mM}$ Tricine buffer at $\mathrm{pH}$ 8.0. AAP was eluted with a $\mathrm{NaCl}$ gradient that ranged from 0 to $1.0 \mathrm{M} \mathrm{NaCl}$ at a flow rate of $1 \mathrm{~mL} / \mathrm{min}$. The purified enzyme was dialyzed against $10 \mathrm{mM}$ Tricine buffer, $\mathrm{pH} 8.0$, containing 0.1 $\mathrm{mM} \mathrm{ZnSO}_{4}$ to remove any remaining $\mathrm{NaCl}$. The enzyme was stored frozen $\left(-80^{\circ} \mathrm{C}\right)$ until needed.

\section{Spectrophotometric Assay of AAP.}

AAP activity was measured by the method of Prescott and Wilkes (1976) as modified by Baker et al. (1983). In this assay, the hydrolysis of $0.5 \mathrm{mM}$ I-leucine- $p$-nitroanilide (10 mM Tricine, $\mathrm{pH}$ 8.0, containing $0.1 \mathrm{mM} \mathrm{ZnSO}_{4}$ ) was measured spectrophotometrically at $25^{\circ} \mathrm{C}$ by monitoring the formation of $p$-nitroaniline. The extent of hydrolysis was calculated by monitoring the increase in absorbance at $405 \mathrm{~nm}\left(\Delta \varepsilon_{405}\right.$ value of $p$-nitroaniline of $10800 \mathrm{M}^{-1} \mathrm{~cm}^{-1}$ ) (Tuppy et al., 1962). One unit was defined as the amount of enzyme that releases $1 \mu \mathrm{mol}$ of $p$ nitroaniline at $25^{\circ} \mathrm{C}$ in $60 \mathrm{~s}$. The specific activity of purified AAP was typically found to be 120 units/mg of enzyme. This value is identical to that reported by Prescott and Wilkes (1976). All spectrophotometric assays were performed on a Shimadzu UV-3101PC spectrophotometer equipped with a constant-temperature cell holder. Enzyme concentrations were determined from the absorbance at $278 \mathrm{~nm}$ with the value $\varepsilon_{278}=$ $41800 \mathrm{M}^{-1} \mathrm{~cm}^{-1}$ (Prescott et al., 1971).

\section{Kinetic Studies.}

The kinetic parameters $v$ (velocity), $k_{\text {cat }}\left(V_{\max } /[\mathrm{E}]_{0}\right), K_{\mathrm{m}}$ (Michaelis constant), and $K_{\mathrm{i}}$ (inhibition constant) were determined at various $\mathrm{pH}$ values between 6.5 and 9.5 spectrophotometrically by recording the initial velocity of the hydrolysis of I-leucine- $p$-nitroanilide at $25^{\circ} \mathrm{C}$ in triplicate. NaF concentrations ranged from 0 to $1 \mathrm{M}$ depending on the $\mathrm{pH}$ of the experiment performed. The linearity of the progress curves for product formation both in the absence and in the presence of inhibitor indicated that fluoride was in rapid equilibrium with AAP. Depletion of enzyme-bound zinc was prevented by the addition of $0.1 \mathrm{mM} \mathrm{ZnSO}_{4}$ to all buffers. Buffers used in the $\mathrm{pH}$ studies were Mops (pH 6.0 and 6.5), Tricine (pH 7.5, 8.0, and 8.7), and boric acid (pH 9.0 and 9.5). The inhibitory nature of boric acid was investigated and found to be a weak competitive inhibitor $\left(K_{\mathrm{i}} \sim 0.3 \mathrm{M}\right)$. These data are in excellent agreement with the previous results of Baker and Prescott (1983); hence, the inhibitory nature of the remaining buffers was not tested, but the reported $K_{\mathrm{i}}$ values (all greater than $0.3 \mathrm{M}$ ) reported by Baker and Prescott were used.

\section{Results}

\section{Inhibition of AAP by Fluoride at pH 8.0.}

Monovalent anions such as fluoride have been used extensively to probe water or hydroxide binding to active site metal centers in metalloproteases (Dixon et al., 1980; Bertini \& Luchinat, 1984; Vallee \& Galdes, 1984; 
Williams \& Auld, 1986; Ganzhorn \& Chanal, 1990; Vincent et al., 1991; Lee \& Nowak, 1992; Yang et al., 1994). In order to elucidate if a metal-centered water/hydroxide participates as the reactive nucleophile in the hydrolysis reaction catalyzed by AAP, the inhibition of fluoride toward the hydrolysis of I-leucine- $p$-nitroanilide by AAP was investigated. The initial rates of hydrolysis of I-leucine- $p$-nitroanilide were monitored as a function of $\mathrm{NaF}$ concentration in $10 \mathrm{mM}$ Tricine buffer, $\mathrm{pH}$ 8.0, containing $0.1 \mathrm{mM} \mathrm{ZnSO}_{4}$. Triplicate activity assay determinations at six concentrations of $\mathrm{NaF}(0-160 \mathrm{mM})$ were made for each of five substrate concentrations $(2-60 \mu \mathrm{M})$. The results are shown in Figure $1 \mathrm{~A}$ as plots of velocity (v) vs substrate concentration ([S]). As shown in Figure 1B, a double-reciprocal plot of velocity vs [NaF] shows a pattern characteristic of uncompetitive inhibition. The experimental data were fit to the Michaelis-Menten equation for uncompetitive inhibition reported by Cleland (1979). Under these conditions, the Michaelis constant $\left(K_{m}\right)$ value for I-leucine-p-nitroanilide was found to be 19 $\mu \mathrm{M}$, in excellent agreement with that previously reported by Prescott et al. (Prescott \& Wilkes, 1976; Baker \& Prescott, 1983). The inhibition constant, $K_{\mathrm{i}}$, for the binding of fluoride ion to AAP was found to be $30 \mathrm{mM}$. Similar studies performed with $\mathrm{NaCl}$ instead of $\mathrm{NaF}$ indicated that chloride ion did not inhibit the hydrolysis of I-leucinep-nitroanilide by AAP even up to $\mathrm{NaCl}$ concentrations of $2 \mathrm{M}$ at $\mathrm{pH} 8.0$.
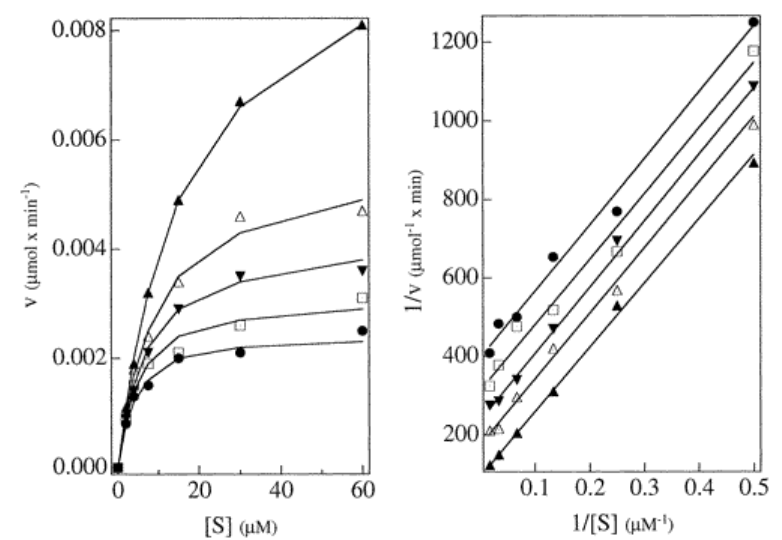

Figure 1 Plot of velocity vs substrate concentration at various fluoride concentrations (A) and the doublereciprocal replot (B). The lines result from a fit of the entire data set to the Michaelis-Menten equation for uncompetitive inhibition. The solutions were buffered with $10 \mathrm{mM}$ Tricine, $\mathrm{pH}$ 8.0. Fluoride concentrations were $0.0(\Delta), 50(\Delta), 80(\cdot), 120(\square)$, and $160 \mathrm{mM}(\cdot)$.

Parallel double-reciprocal plots in the presence of an inhibitor can result from pure uncompetitive inhibition in which the ES complex must form before the inhibitor can bind, leading to an inactive ESI complex. However, parallel double-reciprocal plots can also result from partial uncompetitive inhibition. In this scheme, the inhibitor binds to the ES complex much more tightly than to the enzyme, and ESI is converted much more slowly to $\mathrm{EI}+\mathrm{P}$ than $\mathrm{ES}+\mathrm{I}$. These two cases can be distinguished by plotting the intercepts of $1 / V_{\max }$ from doublereciprocal plots and $1 / K_{\text {mapp }}$ vs [I]. For pure uncompetitive inhibition, a linear relationship is expected, but for partial uncompetitive inhibition, a hyperbolic curve is expected (Segel, 1975). Both replots, shown in Figure 2, are linear and show that fluoride is a pure uncompetitive inhibitor of the hydrolysis of I-leucine- $p$-nitroanilide by AAP. 

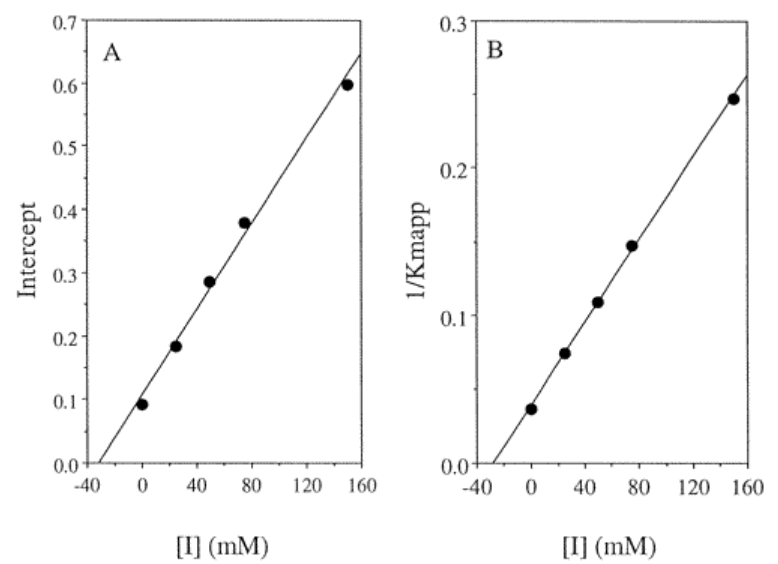

Figure 2 Replot of the data from Figure 1 for the hydrolysis of I-leucine- $p$-nitroanalide by AAP. (A) Intercepts of $1 / V_{\max }$ vs [I]. (B) $1 / K_{\text {mapp }}$ vs [I].

\section{pH Dependence of the Inhibition of AAP by Fluoride.}

In order to determine if fluoride ions displace the nucleophilic water/hydroxide ion at the AAP active site, the inhibitory nature of fluoride on the hydrolysis of I-leucine- $p$-nitroanilide was studied as a function of $\mathrm{pH}$. $k_{\text {cat }}$ was found to be $\mathrm{pH}$-independent over the entire $\mathrm{pH}$ range studied; however, the value of $K_{\mathrm{m}}$ was $\mathrm{pH}$-dependent between $\mathrm{pH}$ values of 6.0 and 10.0. At pH 6.0, $K_{\mathrm{m}}$ was found to be $210 \mu \mathrm{M}$ but decreased to $19 \mu \mathrm{M}$ at pH 8.0. The value of $K_{\mathrm{m}}$ remained constant between pH 8.0 and 9.5; however, it increased slightly to $31 \mu \mathrm{M}$ at pH 10 . These results are in excellent agreement with those previously reported by Baker et al. (1983). Over the pH range 6.0-9.0, fluoride ion acts as a pure uncompetitive inhibitor of AAP, and the $K_{\mathrm{i}}$ increases from 1.2 to 370 $\mathrm{mM}$. A plot of $\mathrm{p} K_{\mathrm{i}} \mathrm{Vs} \mathrm{pH}$ in this range is shown in Figure 3. These data are consistent with the occurrence of a single deprotonation process such as a water molecule to an hydroxide. From these data, the $\mathrm{p} K_{\mathrm{a}}$ value for the bound nucleophile was calculated to be $7.0 \pm 0.3$ (Segel, 1975).

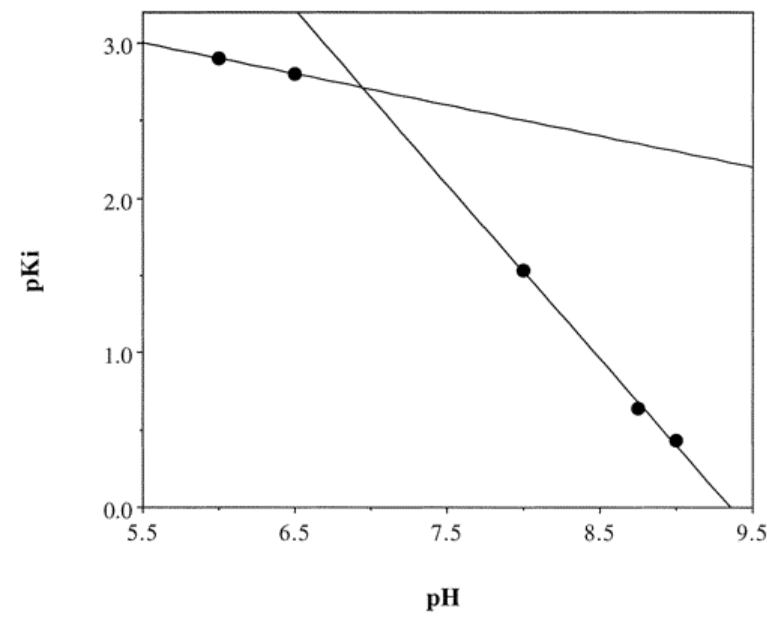

Figure $3 \mathrm{pH}$ dependence of the fluoride ion Michaelis constant $\left(K_{\mathrm{i}}\right)$ for the hydrolysis of I-leucine- $p$-nitroanalide by AAP. The $\mathrm{p} K_{\mathrm{i}}$ data for fluoride inhibition at various $\mathrm{pH}$ values were calculated from initial velocity data fitted to the Michaelis-Menten equation for uncompetitive inhibition.

At $\mathrm{pH}$ values greater than 9.0, the fluoride inhibition pattern changed to competitive with a $K_{\mathrm{i}}$ of $150 \mathrm{mM}$ (Figure 4). Since very high concentrations of $\mathrm{NaF}$ were needed $(>1 \mathrm{M})$ to determine the $K_{\mathrm{i}}$ at these high pH values, it was postulated that the ionic strength of the solution was affecting the catalytic process (Dixon et al., 1980; Todd \& Hausinger, 1989). Therefore, we determined the inhibition pattern of AAP hydrolysis of I-leucine- $p$-nitroanilide 
at $\mathrm{pH} 9.5$ in the presence of $\mathrm{NaCl}$ and tetrabutylammonium fluoride (TBAF) and chloride (TBACl). Each of these salts was found to be a competitive inhibitor of AAP. Since $\mathrm{NaCl}$ does not inhibit AAP at pH 8.0 up to concentrations of $2 \mathrm{M}$, it appears that ionic strength affects the catalytic reaction of AAP at $\mathrm{pH}$ values above 9.0. The change in inhibition pattern for $\mathrm{NaF}$ was attributed to the change in ionic strength or perhaps $\mathrm{pH}$ of the solution since fluoride ion was also found to be a competitive inhibitor of AAP at pH 8.0 in the presence of $2 \mathrm{M}$ $\mathrm{NaCl}$ (Inouye et al., 1996). Since high salt concentrations and pH typically disrupt hydrogen bond formation, these data suggest that hydrogen bond formation may be important in the catalytic process.

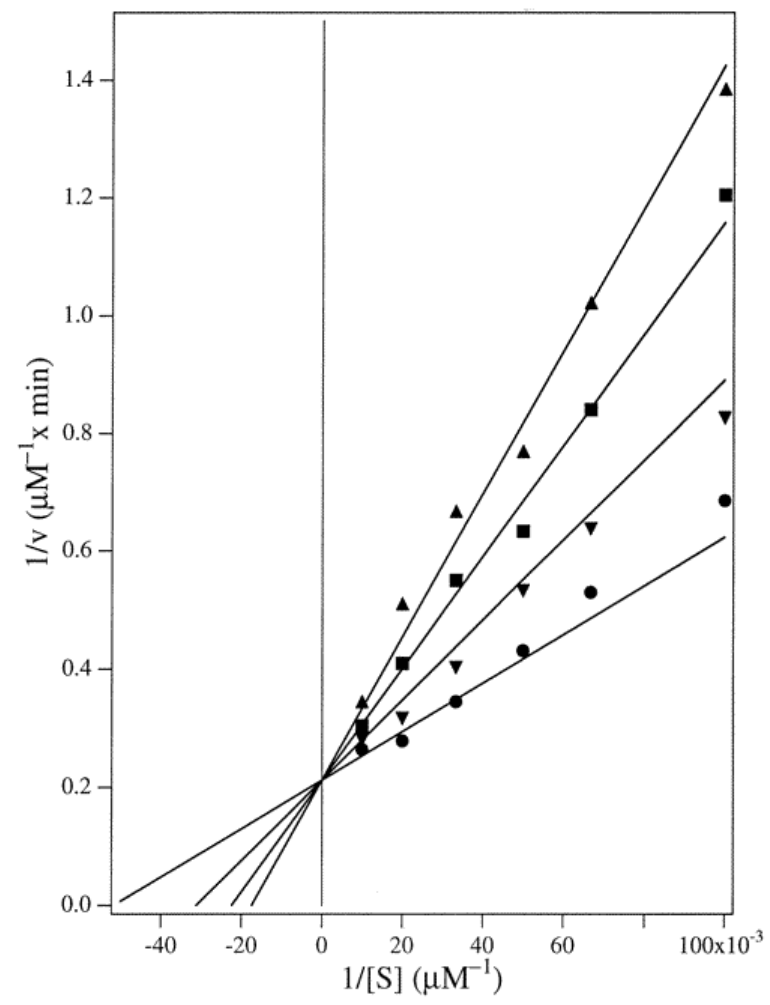

Figure 4 Double-reciprocal plots for the hydrolysis of I-leucine- $p$-nitroanalide by AAP in the presence of NaF at $\mathrm{pH}$ 9.5. The lines result from a fit of the entire data set to the Michaelis-Menten equation for competitive inhibition. The solutions were buffered with $10 \mathrm{mM}$ borate, pH 9.5. Fluoride concentrations were $0.0(\cdot), 100$ ( v), 200 ( $\square), 300 \mathrm{mM}(\Delta)$.

\section{Temperature Dependence of the Hydrolysis of I-Leucine-p-nitroanilide by AAP.} It was previously reported that AAP was stable at $70{ }^{\circ} \mathrm{C}$ for several hours. We have confirmed the thermal stability of AAP and have found that AAP is stable at $70^{\circ} \mathrm{C}$ for a minimum of $5 \mathrm{~h}$. This thermal stability provides the unique opportunity to probe the thermodynamic properties for the AAP-catalyzed hydrolysis of $\mathrm{N}$-terminal amino acids (Segel, 1975). The hydrolysis of I-leucine-p-nitroanilide (10 mM Tricine, pH 8.0, containing $0.1 \mathrm{mM}$ $\mathrm{ZnSO}_{4}$ ) was measured spectrophotometrically in triplicate between 25 and $85^{\circ} \mathrm{C}$ at eight substrate concentrations ranging from 5 to $800 \mu \mathrm{M}$. From these data, $K_{\mathrm{m}}$ values were derived by fitting the experimental data to the Michaelis-Menten equation at each temperature studied (Figure 5). The calculated $V_{\max }$ values are plotted as a function of temperature between 25 and $85{ }^{\circ} \mathrm{C}$ (Figure 5). AAP was found to be stable at $85^{\circ} \mathrm{C}$ for approximately $1 \mathrm{~min}$ before loss in the enzymatic activity was detected. Up to temperatures of $70^{\circ} \mathrm{C}, V_{\max }$ was found to be fully reversible as a function of temperature. These data are very unusual since most enzymes undergo some denaturation at temperatures above $50^{\circ} \mathrm{C}$, resulting in a decrease in $V_{\max }$ (Segel, 1975). 


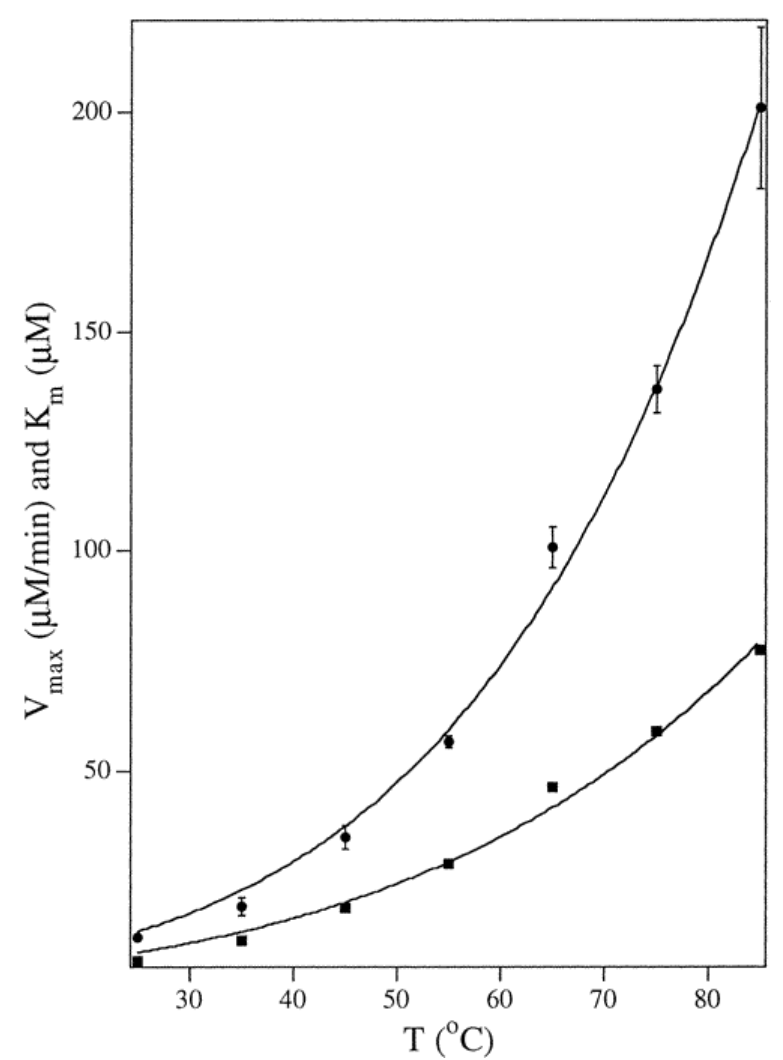

Figure $5 V_{\max }$ Vs temperature (-) and $K_{\mathrm{m}}$ vs temperature (·) for the AAP catalyzed hydrolysis of I-leucine- $p$ nitroanalide at substrate concentrations ranging from 0 to $800 \mu \mathrm{M}(10 \mathrm{mM}$ Tricine, $\mathrm{pH} 8.0$, containing $0.1 \mathrm{mM}$ $\mathrm{ZnSO}_{4}$ ). Each point was measured in triplicate, and the data were fit to the Arrhenius equation.

In a simple rapid equilibrium, $V_{\max } /[\mathrm{E}]=k_{\mathrm{p}}$, the first-order rate constant. Since the enzyme concentration was not altered over the course of the experiment, an Arrhenius plot can be constructed by plotting $\ln k_{\text {cat }}$ vs $1 / T$ (Figure 6). A linear plot was obtained, indicating that the rate-limiting step does not change as the temperature is increased (Segel, 1975). From the slope of the line, the activation energy for temperatures between 298 and 358 $\mathrm{K}, E_{\mathrm{a}}$, was calculated to be $36.5 \mathrm{~kJ} / \mathrm{mol}$ since slope $=-E_{\mathrm{a} 1} / R$ where $R=8.3145 \mathrm{~J} \mathrm{~K}^{-1} \mathrm{~mol}^{-1}$. Other thermodynamic parameters were calculated by the following relations: $\Delta G^{\ddagger}=-R T \ln \left(k_{\mathrm{cat}} h / k_{\mathrm{B}} T\right), \Delta H^{\ddagger}=E_{\mathrm{a}}-R T$, and $\Delta S^{\ddagger}=\left(\Delta H^{\ddagger}-\right.$ $\left.\Delta G^{*}\right) / T$, where $k_{\mathrm{B}}, h$, and $R$ are the Boltzmann, Planck, and gas constants, respectively. The enthalpy and entropy of activation at $25^{\circ} \mathrm{C}$ calculated over the temperature range $298-358 \mathrm{~K}$ were calculated to be $34.0 \mathrm{~kJ} / \mathrm{mol}$ and $-94.2 \mathrm{~J} /(\mathrm{mol} \cdot \mathrm{K})$, respectively. The free energy of activation at $25^{\circ} \mathrm{C}$ was found to be $62.1 \mathrm{~kJ} / \mathrm{mol}$. 


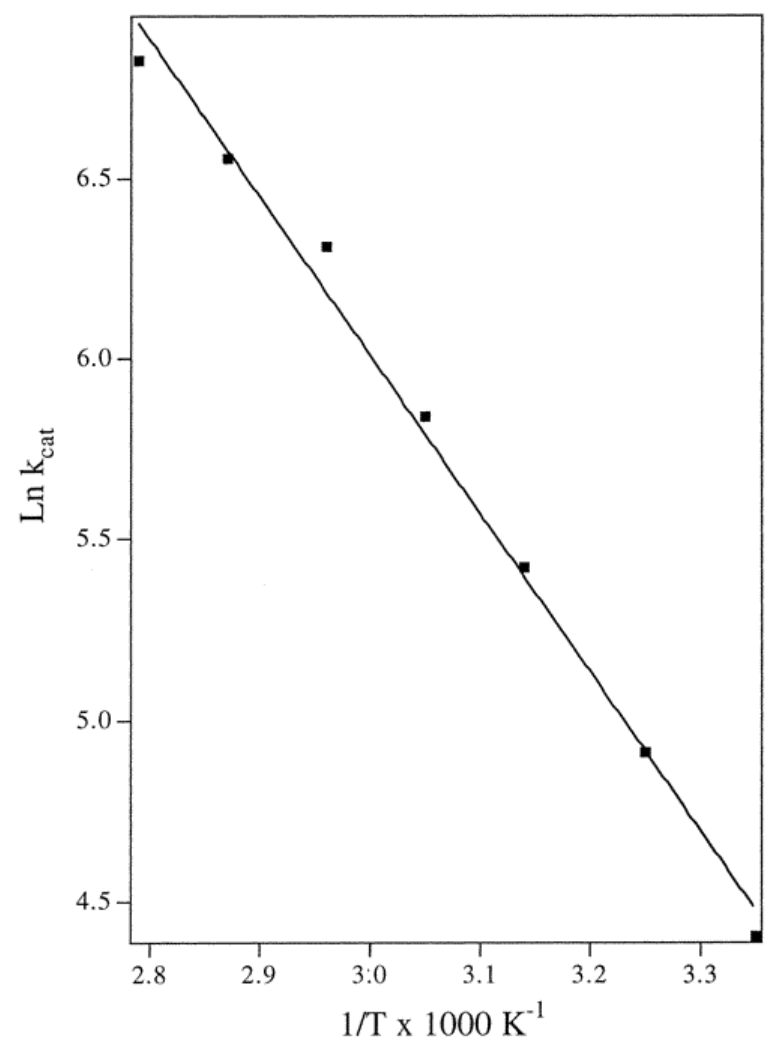

Figure 6 Arrhenius plot of $\ln k_{\text {cat }}$ vs $1 / T$. The line is a direct fit to the Arrhenius equation.

Thermal stability in enzymes has been shown to be dependent on protein structure such as disulfide bonds, $\alpha$ helices, and $\beta$-sheets. Inspection of the X-ray crystalstructure of AAP reveals that AAP contains an eight-stranded $\beta$-sheet and seven structurally equivalent $\alpha$-helices as well as a single disulfide bond at the back of a hydrophobic pocket (Chevrier et al., 1994). Since AAP is an enzyme with a mass of $32 \mathrm{kDa}$, the $\beta$-sheet and $\alpha$ helices contain over $50 \%$ of the amino acids in the polypeptide chain. Prescott et al. (Prescott \& Wilkes, 1976) previously reported that AAP retained $c a .80 \%$ of its activity in $8 \mathrm{M}$ urea, suggesting that AAP was not denatured under these conditions. We confirmed that AAP is $c a .80 \%$ as active in $6 \mathrm{M}$ urea and $6 \mathrm{M}$ guanidinium hydrochloride by monitoring the hydrolysis of $0.5 \mathrm{mM}$ I-leucine- $p$-nitroanilide $(50 \mathrm{mM}$ Hepes, $\mathrm{pH} 8.0,0.2 \mathrm{M} \mathrm{NaCl}$ containing $0.1 \mathrm{mM} \mathrm{ZnSO}_{4}$ ) by AAP that was dialyzed overnight against $6 \mathrm{M}$ urea or guanidinium hydrochloride in the assay buffer. If the stabilization of AAP were primarily due to the high amounts of $\beta$-sheet and $\alpha$-helical structure, the presence of denaturant should cause a substantial loss in activity. Recent ${ }^{1} \mathrm{H}$ NMR studies on the thermal stabilization of the $\mathrm{Zn}$ (II)-containing rubredoxin from Clostridium pasteurianum suggested that the thermal stability of this enzyme was not dominated by $\mathrm{N}$-terminal $\beta$-sheet formation and that an overall tighter protein structure does not necessarily lead to increased thermal stability (Richie et al., 1996). In light of these results, we propose that the thermal stability of AAP is primarily regulated by disulfide bond formation rather than the $\beta$-sheet and $\alpha$-helical structure.

\section{Discussion}

Several aminopeptidases, including AAP, are members of a subclass of metallohydrolases that contain two metal ions in the enzyme active site (Hough et al., 1989; Lebioda \& Stec, 1989; Burley et al., 1990, 1992; Davies et al., 1991; Roderick \& Matthews, 1993; Chevrier et al., 1994; Jabri et al., 1995; Sträter et al., 1995; Wilcox, 1996). For AAP, the two $\mathrm{Zn}$ (II) ions are essential for full enzymatic activity; however, the addition of $1 \mathrm{~mol}$ of $\mathrm{Zn}$ (II) to apoAAP provides an enzyme with $c a$. $80 \%$ of its native enzymatic activity. Substitution of one or both $\mathrm{Zn}$ (II) ions in 
AAP with $\mathrm{Co}(\mathrm{II}), \mathrm{Cu}(\mathrm{II})$, or $\mathrm{Ni}(\mathrm{II})$ provides different magnitudes of activity that are dependent on the sequence and order of addition (Prescott et al., 1983, 1985; Bayliss \& Prescott, 1986). Therefore, both metal ions are required for full activity, but the exact roles of each metal ion in catalysis are unknown. In order to gain insight into the role of the dinuclear active site in catalysis, the inhibition of AAP by fluoride ion was examined. Fluoride is a pure uncompetitive inhibitor of AAP at pH 8.0 with a $K_{\mathrm{i}}$ of $30 \mathrm{mM}$. Thus, fluoride inactivates AAP only after substrate binding and only a single fluoride ion binds to AAP. These data, taken together with previous kinetic studies of mono- and dinuclear hydrolases with fluoride ion, suggest that a Zn(II)-bound water/hydroxide exists at the dimetal active site of AAP and that this water/hydroxide acts as the active site nucleophile. Since AAP is partially active with only one metal ion bound, the water molecule bridging between the two $\mathrm{Zn}$ (II) ions likely becomes terminal after substrate binding, and the resulting nucleophilic water/hydroxide is bound to the first $\mathrm{Zn}(\mathrm{II})$ site (Scheme 1).

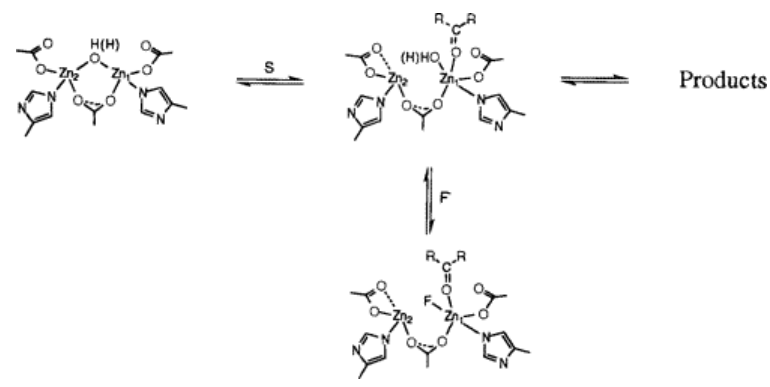

Scheme 1

An interesting finding in this study is the fact that chloride ions do not inhibit the action of AAP up to concentrations of $2 \mathrm{M}$ at $\mathrm{pH}$ 8.0. The difference in fluoride and chloride inhibition behavior can be rationalized by inspection of the X-ray crystal structure of AAP and the relative hardness of the two halide bases. In AAP, the two $\mathrm{Zn}(\mathrm{II})$ ions reside in a carboxylate-rich coordination environment and exhibit tetrahedral geometries (Chevrier et al., 1994). This ligation sphere results in $\mathrm{Zn}(\mathrm{II})$ ions that are relatively hard acids (Martell \& Hancock, 1996). It is well established that the relative order of binding of halide ions to hard acids is $\mathrm{F}^{-} \gg \mathrm{Cl}^{-}>\mathrm{Br}^{-}>$ I- (Cotton \& Wilkinson, 1980; Martell \& Hancock, 1996). Therefore, fluoride ion is expected, and shown, to bind to the $\mathrm{Zn}(\mathrm{II})$ ions in AAP more strongly than chloride ions. These results are similar to those reported for the purple acid phosphatase (PAP) from bovine spleen (Vincent et al., 1991). The PAP from bovine spleen has been shown by spectroscopic methods and X-ray crystallographic studies on a related PAP from kidney bean (Sträter et al., 1995) to contain a non-heme diiron(II,III) active site in which the iron ions reside in carboxylate-rich coordination environments. Similar to AAP, the PAP from bovine spleen is inhibited by fluoride but not chloride ion (Vincent et al., 1991). This is in contrast to the mononuclear Zn(II) active sites in carboxypeptidase A and thermolysin, for example, that reside in histidine-rich coordination environments and are inhibited by both fluoride and chloride ions (Matthews, 1988; Christianson \& Lipscomb, 1989). Both of these enzymes have been shown to contain coordinated water/hydroxide that functions as the nucleophile in catalysis.

The $\mathrm{pH}$ dependence of fluoride inhibition of AAP also suggests that a coordinated water/hydroxide molecule acts as the nucleophile in catalysis. A $\mathrm{p} K_{\mathrm{a}}$ value for this process based on the $\mathrm{p} K_{\mathrm{i}}$ of fluoride inhibition was found to be 7.0. Therefore, at $\mathrm{pH} \mathrm{8.0,} \mathrm{the} \mathrm{pH}$ of maximal activity, the bound nucleophile is primarily in the form of a hydroxide ion. The previously reported $\mathrm{p} K_{\mathrm{a}}$ value for the bound nucleophile, based on the $\mathrm{pH}$ dependence of $k_{\mathrm{cat}} / K_{\mathrm{m}}$, was suggested to be 5.3 (Baker \& Prescott, 1983). Based on our data, it seems more likely that at a pH value of 5.3 the change in $K_{\mathrm{m}}$ reflects $\mathrm{Zn}$ (II) ion binding to AAP. Baker and Prescott (1983) noted that excess $\mathrm{Zn}$ (II) was required at $\mathrm{pH}$ values less than 6.5 because of observed decreased activity levels due to loss of metal ions. Since the active site of AAP is carboxylate-rich, the $p K_{a}$ value of 5.3 likely reflects the deprotonation of glutamate or aspartate moieties that are known to have $\mathrm{p} K_{\mathrm{a}}$ 's between 4.5 and 5.0 (Chevrier et al., 1994). Alternatively, the 
recent X-ray structure of a transition state analog inhibited state of AAP indicates that Glu151 forms a hydrogen bond to the bridging alkoxide group of the hydroxamate inhibitor (Chevrier et al., 1996). The $p K_{\mathrm{a}}$ value determined by Baker and Prescott (1983) may, in fact, reflect the $\mathrm{p} K_{\mathrm{a}}$ of this active site glutamate. The fact that increased $\mathrm{pH}$ and ionic strength alters the kinetics from pure uncompetitive to competitive inhibition supports this since high $\mathrm{pH}$ values and/or salt concentrations would interfere with hydrogen bond formation, thus disrupting the function of Glu151.

An important question for AAP hydrolysis of $\mathrm{N}$-terminal amino acids and dinuclear hydrolases in general is: "What is the rate-limiting step in the catalytic reaction? Since AAP has been shown to be thermally stable at 85 ${ }^{\circ} \mathrm{C}$, AAP provides the unique opportunity to determine the activation parameters of the ES complex over a wide temperature range. Construction of an Arrhenius plot from the temperature dependence of AAP activity indicates that the rate-limiting step does not change as a function of temperature and is product formation (Segel, 1975). The activation energy $\left(E_{\mathrm{a}}\right)$ for the activated $\mathrm{ES}^{\ddagger}$ complex is $36.5 \mathrm{~kJ} / \mathrm{mol}$, which is similar to activation energies determined for the aminopeptidase from Pronase and from both thermolysin and carboxypeptidase A (Lumry et al., 1951; Kunugi et al., 1982; Wu \& Lin, 1995). The enthalpy and entropy of activation calculated over the temperature range $25-85^{\circ} \mathrm{C}$ are $34.0 \mathrm{~kJ} / \mathrm{mol}$ and $-94.2 \mathrm{~J} /(\mathrm{mol} \cdot \mathrm{K})$, respectively, at $25{ }^{\circ} \mathrm{C}$. The large positive enthalpy is indicative of a conformation change upon substrate binding, likely due to the energy of bond formation and breaking during the nucleophilic attack on the scissile carbonyl carbon of the substrate. On the other hand, the large negative entropy value suggests that some of the molecular motions are lost upon $\mathrm{ES}^{\ddagger}$ complex formation possibly due to hydrogen bond formation between Glu151 and/or Try225 (two amino acids recently implicated as catalytically important) and the substrate. All of these factors contribute to the large positive free energy of activation.

Combination of the available X-ray crystallographic data with the present kinetic and thermodynamic studies, as well as the previously reported kinetic and spectroscopic data (Bennett \& Holz, 1997), allows a detailed catalytic mechanism to be proposed for AAP (Figure 7). Since an active site carboxylate group, Glu151, has been implicated in the catalytic process from X-ray crystallographic data, the catalytic mechanism of AAP likely resembles that proposed for thermolysin and carboxypeptidase $A$ (Chevrier et al., 1996). For AAP, the incoming peptide interacts with Tyr255 in the hydrophobic pocket through a hydrogen bond with the N-terminus. Glu151 also forms hydrogen bonds with the bridging water molecule as well as the penultimate peptide NH hydrogen. Based on X-ray crystallographic data of a transition-state analog inhibitor bound AAP complex, the carbonyl oxygen of the peptide binds directly to a single $\mathrm{Zn}(\mathrm{II})$ ion. This binding scheme is consistent with the large negative entropy and large positive enthalpy of activation. 


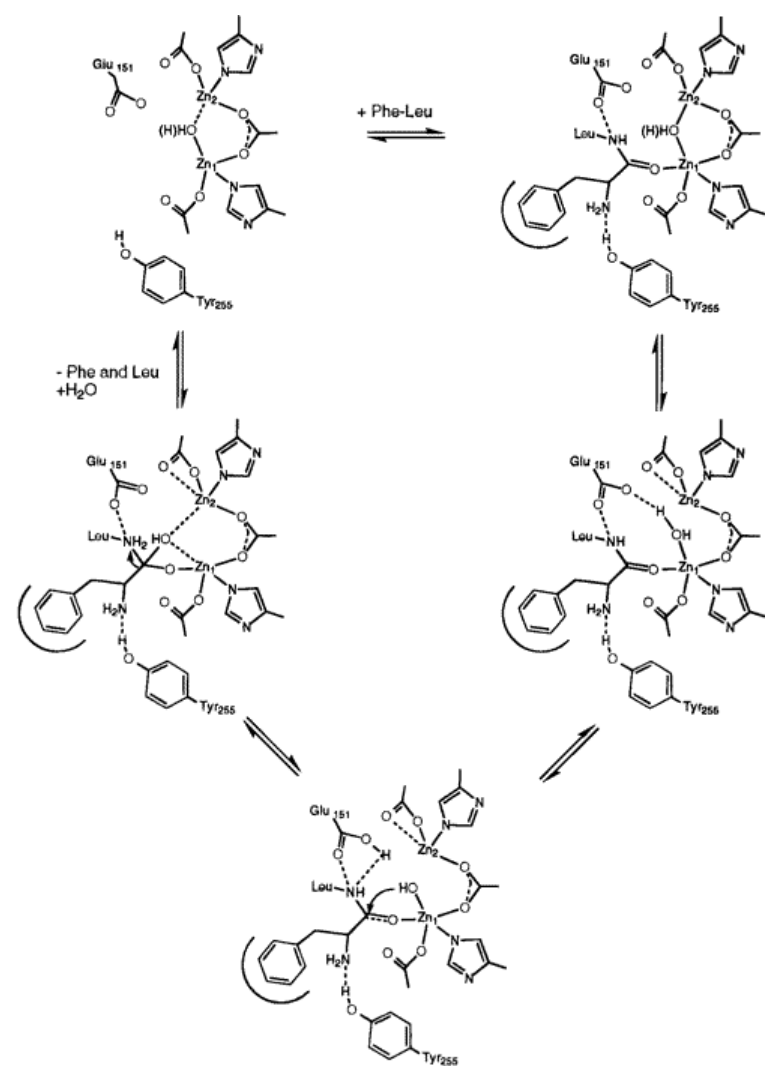

Figure 7 Proposed catalytic mechanism of AAP catalysis. The mechanism is discussed in the text.

Since AAP is ca. $80 \%$ active with only a single $\mathrm{Zn}(\mathrm{II})$ ion bound and fluoride binding occurs only after substrate binding, it seems likely that the bridging water molecule becomes terminal upon substrate binding and is bound to the catalytic $\mathrm{Zn}$ (II) site. This is consistent with the relative paucity of discrete dinuclear model complexes with fluoride bridging moieties as well as the increase in the $\mathrm{Zn}-\mathrm{Zn}$ distance upon inhibitor binding from 3.5 to $3.7 \AA$ (Chevrier et al., 1994). This requires that the coordination number of the catalytic $\mathrm{Zn}(\mathrm{II})$ ion increases from 4 to 5. Electronic absorption data for [Co_(AAP)], [CoCo(AAP)], and [ZnCo(AAP)] suggest a tetrahedral environment for the first metal binding site and an octahedral site for the second (Prescottet al., 1983). The only spectroscopic data available on inhibitor binding to AAP are derived from electronic absorption and EPR studies on the Co(II)-substituted enzyme (Prescott et al., 1985; Bennett \& Holz, 1997). Based on the comparison of absorption and EPR data recorded on [Co_(AAP)], [CoCo(AAP)], and [ZnCo(AAP)] in the presence and absence of the competitive inhibitor butaneboronic acid (BuBA), it was proposed that BuBA binds to the catalytic metal ion but not to the second metal ion. These data, as well as the thermodynamic results presented herein, are consistent with the proposal that in the transition state the first $\mathrm{Zn}(\mathrm{II})$ ion becomes 5-coordinate. Four coordination of the second metal ion is likely maintained by binding Asp179 in a bidentate fashion since the $\mathrm{Zn}-\mathrm{O}$ bond distance for the second oxygen atom of Asp179 from X-ray crystallography is $2.34 \AA$ (Chevrier et al., 1994). Alternatively, a water molecule may bind to the second $\mathrm{Zn}(I I)$ ion, which is consistent with the electronic absorption data for the [ZnCo(AAP)] enzyme which indicate that the second Co(II) ion is 6-coordinate (Prescott et al., 1985).

Bertini et al. (1990) have shown that an increase in coordination number from 4 to 6 for Zn(II) complexes with a bound water molecule steadily increases the energy of conversion between an hydroxo and a water moiety. This increase in energy was related to an increase in $\mathrm{p} K_{\mathrm{a}}$; thus, the higher the coordination number, the higher the $\mathrm{p} K_{\mathrm{a}}$. A similar trend is observed as the number of carboxylate ligands to a $\mathrm{Zn}(\mathrm{II})$ ion increases (Bertini et al., 1990). Therefore, the role of Glu151 is likely to assist in deprotonation of the terminal water molecule to the 
nucleophilic hydroxo moiety, similar to that of Glu270 in carboxypeptidase A (Christianson \& Lipscomb, 1989). At this point, the metal-bound hydroxide can attack the activated scissile carbonyl carbon of the peptide substrate, forming a gem-diolate intermediate complex that is stabilized by coordination of both oxygen atoms to the dizinc(II) center. Glu151 can then provide an additional proton to the penultimate amino nitrogen returning to its ionized state. The $\mathrm{C}-\mathrm{N}$ bond breaking step would likely be the rate-limiting step, which would be consistent with our thermodynamic results. Finally, the dinuclear $\mathrm{Zn}(\mathrm{II})$ cluster releases the cleaved peptides and adds a water molecule that bridges between the two metal ions.

Recently, information regarding the mechanism of action of bILAP was reported. Based on X-ray crystallographic results of several inhibited forms of bILAP, it was proposed that both of the active site metal ions act as Lewis acids and that the resulting bridging hydroxide ion attacks the scissile carbonyl carbon of the peptide substrate (Sträter \& Lipscomb, 1995a,b). According to the X-ray structure of the I-leucinal-bound bILAP complex (Sträter \& Lipscomb, 1995a,b), the substrate is stabilized by binding to both metal ions [i.e., the N-terminal amine binds to one Zn(II), and the peptide carbonyl group binds to the second Zn(II)]. The substrate also interacts with Lys 262 and Arg336. Lys262 appears to assist in polarizing the peptide carbonyl group which is also coordinated to the dizinc(II) cluster. Arg336 interacts with the substrate via active site water molecules. Within this pocket, a short O-O bond was observed ( $2.3 \AA$ ) that is much too short for a hydrogen bond. Sträter and Lipscomb $(1995 a, b)$ have proposed that an $\mathrm{H}_{3} \mathrm{O}_{2}^{-}$(bihydroxide) is present and is stabilized by the positively charged $\mathrm{Arg} 336$ residue in the active site pocket. In a similar structure, $\mathrm{NaHCO}_{3}$ was shown to bind in the same manner as bihydroxide. The role of the bihydroxide in the catalytic mechanism is as yet unclear, but Sträter and Lipscomb $(1995 a, b)$ have proposed that the bihydroxide functions as a general base.

Comparison of the proposed catalytic mechanism of AAP and bILAP indicates some striking differences, but also suggests some important similarities that may shed light on the catalytic mechanism of dinuclear hydrolases in general. First, the N-terminal amino group of the peptide substrate binds one of the $\mathrm{Zn}$ (II) ions in bILAP while the carbonyl oxygen binds the second Zn(II) ion (Burley et al., 1992; Kim \& Lipscomb, 1993a,b). This is in marked contrast to AAP in which the N-terminal amine group hydrogen bonds to Tyr255 in the hydrophobic pocket, and the carbonyl group binds the catalytic Zn(II) ion (Chevrier et al., 1996). Moreover, Sträter and Lipscomb proposed that the bridging hydroxide moiety in bILAP acts as the nucleophile, but attacks from a bridging position (Sträter \& Lipscomb, 1995a,b). This type of nucleophilic attack has also been proposed for the hydrolysis of phosphate diesters by a dinuclear Co(III) model complex (Wahnon et al., 1995), but can be discarded for AAP since AAP exhibits enzymatic activity with only a single $\mathrm{Zn}$ (II) ion bound. Therefore, the active site nucleophile must involve only a single Zn(II) ion with a terminal hydroxide moiety. Similarities in the proposed mechanisms for AAP and bILAP exist in the coordination of a gem-diolate complex for the transition state of bILAP (Sträter \& Lipscomb, 1995a,b). First, a general base in the active site of AAP, namely, Glu151, assists in the catalytic process, whereas bihydroxide $\left([\mathrm{HOHOH}]^{-}\right)$has been proposed to function as the general base in the active site of bILAP (Sträter \& Lipscomb, 1995a,b). In addition, based on the X-ray structure of the transition state analog inhibitor d-iodophenylalanine hydroxamate bound to AAP (Chevrier et al., 1996), the carbonyl oxygen atom binds to the catalytic $\mathrm{Zn}(\mathrm{II})$ ion while the hydroxylamino oxygen atom bridges between the two metal atoms. This is similar to the X-ray crystallographic results for I-leucinal binding to bILAP forming a gem-diolate transition state complex (Sträter \& Lipscomb, 1995a,b). Thus, both metal ions are required for full enzymatic activity of these two aminopeptidases, but their individual roles appear to differ markedly.

\section{Acknowledgment}

We thank Drs. Brian Bennett, Lance Seefeldt, Scott Ensign, and Vernon Parker for helpful discussions. 


\section{References}

Aoyagi, T., Suda, T., Nagai, M., Ogawa, K., Suzuki, J., Takeuchi, T., \& Umezawa, H. (1976) Biochim. Biophys. Acta452, 131-143.

Baker, J. O., \& Prescott, J. M. (1983) Biochemistry22, 5322-5331.

Baker, J. O., Wilkes, S. H., Bayliss, M. E., \& Prescott, J. M. (1983) Biochemistry22, 2098-2103.

Bayliss, M. E., \& Prescott, J. M. (1986) Biochemistry25, 8113-8117.

Ben-Bassat, A., \& Bauer, K. (1987) Nature326, 315.

Ben-Bassat, A., Bauer, K., Chang, S.-Y., Myambo, K., Boosman, A., \& Chang, S. (1987) J. Bacteriol.169, 751-757.

Bennett, B., \& Holz, R. C. (1997) J. Am. Chem. Soc.119, 1923-1933.

Bertini, I., \& Luchinat, C. (1984) Adv. Inorg. Biochem.6, 71-111.

Bertini, I., Luchinat, C., Rosi, M., Sgamellotti, A., \& Tarantelli, F. (1990) Inorg. Chem.29, 1460-1463.

Burley, S. K., David, P. R., Taylor, A., \& Lipscomb, W. N. (1990) Proc. Natl. Acad. Sci. U.S.A.87, 6878-6882.

Burley, S. K., David, P. R., Sweet, R. M., Taylor, A., \& Lipscomb, W. N. (1992) J. Mol. Biol.224, 113-140.

Chevrier, B., Schalk, C., D'Orchymont, H., Rondeau, J.-M., Moras, D., \& Tarnus, C. (1994) Structure2, 283-291.

Chevrier, B., D'Orchymont, H., Schalk, C., Tarnus, C., \& Moras, D. (1996) Eur. J. Biochem.237, 393-398.

Christianson, D. W., \& Lipscomb, W. N. (1989) Acc. Chem. Res.22, 62-69.

Cleland, W. W. (1979) Methods Enzymol.63, 103-138.

Cotton, F. A., \& Wilkinson, G. (1980) Advanced Inorganic Chermistry, 4th ed., John Wiley \& Sons, New York.

Davies, J. F., Hostomska, Z., Hostomsky, Z., Jordan, S. R., \& Mathews, D. A. (1991) Science 252, 88-95.

Dixon, N. E., Blakely, R. L., \& Zerner, B. (1980) Can. J. Biochem.58, 481-488.

Ganzhorn, A. J., \& Chanal, M.-C. (1990) Biochemistry29, 6065-6071.

Hough, E., Hansen, L. K., Birknes, B., Jynge, K., Hansen, S., Horvik, A., Little, C., Dodson, E., \& Derewenda, Z. (1989) Nature338, 357-360.

Inouye, K., Lee, S.-B., \& Tonomura, B. (1996) Biochem. J.315, 133-138.

Jabri, E., Carr, M. B., Hausinger, R. P., \& Karplus, P. A. (1995) Science268, 998-1004.

Kim, H., \& Lipscomb, W. N. (1993a) Proc. Natl. Acad. Sci. U.S.A.90, 5006-5010.

Kim, H., \& Lipscomb, W. N. (1993b) Biochemistry32, 8465-8478.

Kunugi, S., Hirohara, H., \& Ise, N. (1982) Eur. J. Biochem.124, 157-163.

Lebioda, L., \& Stec, B. (1989) J. Am. Chem. Soc.111, 8511-8513.

Lee, M. E., \& Nowak, T. (1992) Biochemistry31, 2172-2180.

Liotta, L. A. (1992) Sci. Am.266, 54-63.

Liotta, L. A., Steeg, P. S., \& Stetler-Stevenson, W. G. (1991) Cell64, 327-336.

Lumry, R., Smith, E. L., \& Glantz, R. R. (1951) J. Am. Chem. Soc.73, 4330-4340.

Martell, A. E., \& Hancock, R. D. (1996) Metal Complexes in Aqueous Solution, pp 199-202, Plenum Press, New York.

Matthews, B. W. (1988) Acc. Chem. Res.21, 333-340.

Prescott, J. M., \& Wilkes, S. H. (1976) Methods Enzymol.45B, 530-543.

Prescott, J. M., Wilkes, S. H., Wagner, F. W., \& Wilson, K. J. (1971) J. Biol. Chem.246, 1756-1764.

Prescott, J. M., Wagner, F. W., Holmquist, B., \& Vallee, B. L. (1983) Biochem. Biophys. Res. Commun.114, 646-652.

Prescott, J. M., Wagner, F. W., Holmquist, B., \& Vallee, B. L. (1985) Biochemistry24, 5350-5356.

Richie, K. A., Teng, Q., Elkin, C. J., \& Kurtz, D. M. (1996) Protein Sci.5, 883-894.

Roderick, S. L., \& Matthews, B. W. (1993) Biochemistry32, 3907-3912.

Schalk, C., Remy, J.-M., Chevrier, B., Moras, D., \& Tarnus, C. (1992) Arch. Biochem. Biophys.294, 91-97.

Segel, I. H. (1975) Enzyme Kinetics: Behavior and analysis of rapid equilibrium and steady-state enzyme systems, 1st ed., John Wiley \& Sons, New York. 
Sträter, N., \& Lipscomb, W. N. (1995a) Biochemistry34, 9200-9210.

Sträter, N., \& Lipscomb, W. N. (1995b) Biochemistry34, 14792-14800.

Sträter, N., Klabunde, T., Tucker, P., Witzel, H., \& Krebs, B. (1995) Science268, 1489-1492.

Taylor, A. (1993a) FASEB J.7, 290-298.

Taylor, A. (1993b) Trends. Biochem. Sci.18, 167-172.

Todd, M. J., \& Hausinger, R. P. (1989) J. Biol. Chem.264, 15835-15842.

Tuppy, H., Wiesbauer, W., \& Wintersberger, E. (1962) Hoppe-Seyler's Z. Physiol. Chem.329, 278-288.

Vallee, B. L., \& Galdes, A. (1984) Adv. Enzymol.56, 283-430.

Vallee, B. L., \& Auld, D. S. (1990) Biochemistry29, 5647-5659.

Vincent, J. B., Crowder, M. W., \& Averill, B. A. (1991) Biochemistry30, 3025-3034.

Wahnon, D., Lebuis, A.-M., \& Chin, J. (1995) Angew. Chem., Int. Ed. Engl.34, 2412-2414.

Wilcox, D. E. (1996) Chem. Rev.96, 2435-2458.

Williams, A. C., \& Auld, D. S. (1986) Biochemistry25, 94-100.

Wu, C.-H., \& Lin, W.-Y. (1995) J. Inorg. Biochem.57, 79-89.

Yang, J. J., Artis, D. R., \& Van Wart, H. E. (1994) Biochemistry33, 6516-6523.

1 Abbreviations: Tris, tris(hydroxymethyl)aminomethane; AAP, aminopeptidase from Aeromonas proteolytica; bILAP, bovine lens leucine aminopeptidase; MAP, methionine aminopeptidase from E. coli; $v$, velocity; $V_{\max }$, maximal velocity; $k_{\mathrm{cat}}, V_{\max } /[\mathrm{E}]_{\mathrm{o}} ; K_{\mathrm{m}}$, Michaelis constant; $K_{\mathrm{i}}$, inhibition constant; [S], substrate concentration; [I], inhibitor concentration; ES, enzyme-substrate complex; ES₹, activated enzyme-substrate complex; Mops, 3-( $N$-morpholino)propanesulfonic acid; Tricine, $N$ [tris(hydroxymethyl)methyl]glycine; BuBA, 1-butaneboronic acid; TBAF, tetrabutylammonium fluoride; $\mathrm{TBACl}$, tetrabutylammonium chloride. 